\section{Edycação
Por Escrito}

ARTIGO

\section{Editor}

Alexandre Anselmo Guilherme PUCRS, RS, Brasil

\section{Editor Assistente}

Cibele Cheron

PUCRS, RS, Brasi

\section{Editores Associados}

Bruno Antonio Picoli

Universidade Federal da Fronteira Sul, Chapecó, SC, Brasil

Pricila Kohls dos Santos Universidade Católica de Brasília, Brasília, DF, Brasil

Renato de Oliveira Brito

Universidade Católica de Brasilia, Brasilia, DF, Brasil

Elisa Ustarroz

PUCRS, Porto Alegre, RS, Brasil

\section{ISSN 2179-8435}

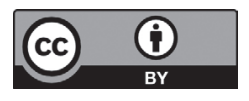

Este artigo está licenciado sob forma de uma licença Creative Commons Atribuiçăo 4.0 Internacional, que penalquer meio, desde que a publicaçăo origçąal seja corretamente citada http://creativecommons.org/licenses/by/4.0/deed.pt_BP

\title{
Dificuldades de comunicação em um curso de licenciatura para os anos iniciais na modalidade de Ensino a Distância ${ }^{1}$
}

\author{
Difficulties of communication in a graduation course for the initial years \\ in the modality of Distance Learning \\ Alberto Luiz Pereira da Costa $\odot$ \\ Universidade Federal do Triângulo Mineiro (UFTM), Uberaba, MG, Brasil.
}

\section{RESUMO}

O objetivo da investigação foi entender como ocorre a comunicação no processo de ensino e aprendizagem entre os docentes universitários responsáveis pelo módulo de geometria e tutores de um Curso Licenciatura para os Anos Iniciais na modalidade de Ensino a Distância, oferecido por uma Universidade Pública do Paraná. Na metodologia nos pautamos na Análise do Discurso nas interações ocorridas via plataforma. Os resultados obtidos ofereceram indícios para entender os problemas relacionados ao EAD. Com nossa pesquisa obtivemos um parâmetro do procedimento desenvolvido na ação educativa, além de analisarmos se essa interação contribui e de que modo para o trabalho a ser desenvolvido por esses tutores com os alunos do curso (os cursistas) em relação aos conteúdos desse conhecimento escolar.

Palavras-chave:: Linguagem. Tutoria. Geometria.

\section{ABSTRACT}

The objective of the research was to understand how communication occurs in the teaching and learning process among the university professors responsible for the geometry module and tutors of a Graduation Course for the Initial Years in the modality of Distance Learning, offered by a Public University of Paraná. In the methodology we are in the Discourse Analysis in the interactions that took place via the platform. The results obtained provided clues to understand the problems related to Distance Education. With our research, we obtained a parameter of the procedure developed in the educational action, besides analyzing if this interaction contributes and in what way to the work to be developed by these tutors with the students of the course (the students) in relation to the contents of this school knowledge.

Keywords: Language. Mentoring. Geometry. 


\section{Introdução}

Tas últimas décadas ocorreu um comprometimento pelos pesquisadores para desenvolverem investigações na 1 formação de professores em vários níveis e modalidades. Diversos pesquisadores empenham-se em discutir a formação de professores em ambientes formais e não-formais, por meio da argumentação, comunicação e linguagem².

Em particular, o modelo de educação a distância vem ocupando cada vez mais espaço, não só em congressos, de educadores das mais diferentes formações, mas também na imprensa. Essas discussões, por sua vez, reverberam na qualificação acadêmica de cada área, denotando que, na maioria das vezes, docentes e pesquisadores de diversas áreas desconhecem as especificidades teórico-pedagógicas da EAD, embora a pratiquem no cotidiano (PERRENOUD, 2002).

Sobre a prática docente Pavanello (2013) ressalta a necessidade de:

Uma prática em que se dê voz aos alunos e não somente ao professor, de modo que nas interações entre todos os envolvidos, o significado matemático não seja imposto, mas passe a ser objeto de negociação, revelando as diferentes possibilidades de interpretação de enunciados ou tarefas entre sujeitos (PAVANELLO, 2013, p. 2).

Essa fala nos leva a inferir que, "embora o século XXI esteja começando, ele ainda tem a mesma característica da última década do século passado. No curto prazo, as orientações que norteiam a formação dos professores não diferem radicalmente daquelas que foram propostas há cinco" (PERRENOUD, 2002, p. 11).

No começo do século XXI, após o governo promulgar a Lei de Diretrizes e Bases que estipula a exigência da formação acadêmica para os professores das séries iniciais, vários educadores tiveram que se aperfeiçoar para continuarem a exercer sua profissão. De acordo com essa lei, a de no 9.394 de 1996, na primeira década deste século XXI todos os professores atuantes no País deveriam ter formação universitária (BRASIL, 1996). Tal fato fez com que muitas instituições universitárias criassem programas especiais de formação de professores.

A formação de professores para séries iniciais do Ensino Fundamental passou para a responsabilidade de escola de nível superior, organizada em um projeto questionado pelos educadores de todo o país - o Curso Normal Superior -, abraçado pelas universidades e faculdades privadas (BITTENCOURT, 2007, p. 9).

2 Para mais informações ver: COSTA; PAVANELLO, 2018, COSTA, 2013, D'ANTONIO; PAVANELLO, 2013; D’ANTONIO, 2010; COSTA; PAVANELLO, 2010; PAVANELLO, 2013. 
A fim de atender a procura por uma formação superior, as universidades optaram, em sua maioria, por oferecer cursos na modalidade a distância. De acordo com Alves e Nova (2003), "no período de 1999 a 2001, foram aprovados 14 cursos de graduação pela Secretaria de Educação Superior (SESU), nas áreas de educação, ciências, biologia, matemática, física e química" (ALVES; NOVA, 2003, p. 4).

Considerar a quantidade de cursos na modalidade de ensino a distância que são oferecidos atualmente pelas universidades com o argumento que o País carece de profissionais qualificados para atuarem no ensino fundamental e médio nos fez refletir sobre a importância de analisar os diferentes aspectos da formação que os futuros professores estão recebendo nesses cursos de formação de professores.

No caso da formação de professores que lecionam Matemática, tornava-se necessário discutir alguns pontos fundamentais: Qual formação esses professores estão recebendo? Que qualidade tem os cursos de formação de professores oferecidos na modalidade a distância? O curso na modalidade a distância está realmente exercendo seu papel na formação? Essas questões serão discutidas e refletidas no decorrer deste artigo na análise dos dados.

\section{A investigação}

O trabalho aqui apresentado tem sua origem em nossas preocupações com a formação dos professores que lecionam Matemática nas séries iniciais do Ensino Fundamental, a qual, segundo alguns estudos, não os tem preparado devidamente para realizar sua prática docente de qualidade com os conteúdos dessa área do conhecimento escolar, especialmente os referentes à geometria. Estamos, além disso, presenciando neste momento essa formação ser cada vez mais delegada a cursos na modalidade a distância, sem, no entanto, uma rigorosa investigação da sua qualidade (COSTA; PAVANELLO, 2011).

O Curso de Licenciatura para os Anos Iniciais, oferecido por uma universidade pública do norte do Paraná na modalidade EAD, contemplava, no ano de 2010, a carga horária de 400 horas destinadas à Matemática. Era dividida em quatro módulos em um dos quais era abordada a geometria, com o objetivo de estudar os principais elementos da geometria plana e espacial e suas aplicações no dia a dia e nas outras ciências.

O fato de a Universidade vir promovendo, desde 2004, cursos de formação de professores para as séries iniciais nessa modalidade foi o que motivou nossa necessidade de analisar mais detalhadamente um processo de ensino e aprendizagem da geometria na EAD e verificar quais possibilidades e limitações de um curso que tem no tutor um papel central: o de fazer a mediação entre os alunos, os docentes do curso de Licenciatura para os Anos Iniciais do Ensino Fundamental na modalidade EAD e o conhecimento geométrico. 
Embora o curso fosse oferecido na modalidade a distância, era prevista a existência de tutores para atender os cursistas nos diferentes polos credenciados para sanar suas dúvidas em relação ao conteúdo do material dos módulos. Para a tutoria poder ser realizada com responsabilidade - principalmente no caso da geometria, área em que estudos mostram que mesmo professores licenciados em Matemática têm dificuldades com os conteúdos - os tutores contavam com a possibilidade de interagir com os docentes universitários responsáveis pelo módulo por meio de uma plataforma online.

Nossa preocupação fundamental era se a interação entre docente e tutor mediante o uso da plataforma era suficiente para sanar as possíveis dificuldades do tutor com relação a esse tema e desenvolver sua aprendizagem de geometria por meio do ambiente virtual.

\section{A pesquisa}

O presente estudo teve como objetivo investigar como ocorre a comunicação nas interações discursivas no ambiente virtual de aprendizagem entre os docentes universitários responsáveis pelo módulo de geometria e os tutores desse Curso Licenciatura para os Anos Iniciais na modalidade de Ensino a Distância. Mais precisamente, o estudo visava verificar se essa interação contribuía e de que modo para o trabalho a ser desenvolvido por esses tutores com os alunos do curso (os cursistas) em relação aos conteúdos desse conhecimento escolar. Para atender a nosso objetivo, adotamos a pesquisa qualitativa de caráter interpretativo. $\mathrm{Na}$ análise das comunicações nos chats, nos pautamos em algumas obras que tratam da Análise do Discurso (BAKHTIN, 2003, 2012; entre outros), que contribuíram para a investigação e o entendimento dialógico entre os personagens das interações. Buscamos também subsídios em autores que discutem a formação de professores pelo uso das Tecnologias da Informação e Comunicação (TIC), tais como: Gouvêa e Oliveira (2006), Giordan (2008), Rezende (2006), Valente e Bustamante (2009).

Para entender como ocorria a interação discursiva e de aprendizagem no ambiente virtual, procuramos analisar algumas questões referentes à comunicação expressa na plataforma: 1) Quais as dificuldades para essa interação? Todos os tutores fazem uso da plataforma? E de que forma? 3) A interação que ocorre permite ao tutor sanar suas dúvidas quanto ao conteúdo de geometria?

A análise proposta neste trabalho foi relevante para compreender quais as possibilidades existentes em um curso na modalidade de Ensino a Distância em que o tutor é um dos responsáveis pela construção do conhecimento pelos cursistas, os futuros professores das séries iniciais, no que diz respeito à geometria. 


\section{Análise dos resultados e discussão}

Da análise das comunicações via internet emergiram questões de argumentação, linguagem, significados relativos também ao próprio entendimento no ambiente on-line. Para este trabalho, selecionamos alguns trechos que mais se aproximavam do nosso objetivo de pesquisa - as dificuldades de comunicação. Os episódios intitulados indagações e inquietações são apresentados por meio de cenas. Nelas, os cursistas e docentes são identificados por nomes fictícios. Neste sentido, iremos exemplificar os motivos, as indignações, as conversas cortadas, o próprio entendimento do conteúdo e as dificuldades - entre outra as relativas aos limites tecnológicos.

\section{Questões relativas à geometria}

Analisamos aqui algumas dificuldades encontradas pelos tutores no que diz respeito à geometria e o diálogo possível estabelecido com o docente universitário a esse respeito - as dificuldades dos tutores com relação aos conteúdos de geometria puderam ser verificadas tanto nos chats e fóruns.

Como a os tutores selecionados para dar suporte à aprendizagem dos cursistas não eram, em sua maioria, formados em Matemática ou especialistas nessa área, o material de apoio para os módulos acabava sendo de difícil compreensão para eles, o que dificultava sua atuação com os cursistas.

O problema ficava ainda mais complicado em se tratando do material do módulo referente aos conteúdos de geometria. Como os tutores tinham o dever de sanar as dúvidas dos cursistas, tornava-se necessário para tanto que esclarecessem antes suas próprias dificuldades com os docentes responsáveis pelo módulo nos espaços destinados a essa interação, os chats e fóruns de discussão.

1. (26/11/2007 18h: 44 min) Tutor Fernando fala para João: Precisaria conferir a correção da atividade 1, página 52, principalmente quanto ao número de arestas do tetraedro, cubo e prisma. Seria possível?

2. (26/11/2007 18h: $45 \mathrm{~min})$ Tutora Helena fala para todos: Marli tem que buscar as provas no Pólo.

3. (26/11/2007 18h: 45 min) Prof. João fala para todos: Tetraedro: 6 faces.

4. (26/11/2007 18h: $45 \mathrm{~min})$ Tutor Fernando fala para todos: Sim!!!

5. (26/11/2007 18h: 45 min) Prof. João fala para todos: Perdão... 4 faces.

6. (26/11/2007 18h: 45 min) Prof. João fala para Todos: 6 arestas.

7. (26/11/2007 18h: 45 min: 44) Tutor Fernando fala para todos: e arestas!

8. (26/11/2007 18h: 45 min) Prof. João fala para Todos: 4 vértices... ${ }^{3}$

\footnotetext{
3 COSTA; PAVANELLO, 2018. Recorte do chat da interação geométrica do curso EAD, Paraná, 2018, Plataforma e-Proinfo.
} 
Selecionamos esse episódio intitulado indagações porque percebemos alguns problemas na comunicação entre os envolvidos neste diálogo. Faz-se necessário esclarecer que suprimimos algumas falas presentes neste episódio. No início desta interação o professor universitário tenta sanar a dúvida do tutor referente ao conteúdo presente nas páginas 52-53 do material de apoio, o volume destinado ao tema Espaço e Forma.

O tutor, ao conferir com o docente a quantidade de faces, arestas e vértices de cada um dos poliedros (tetraedro, cubo, prisma) da atividade proposta, percebeu na resposta do docente um equívoco no que diz respeito ao número de faces do tetraedro (sequência 3) e o diálogo acabou retornando ao erro em outra cena. Vale ressaltar que o docente percebeu o fato, chamou a atenção para o quanto era importante ficar atento aos diversos discursos que ocorrem ao mesmo tempo em um texto postado no espaço do fórum de discussão, voltou à questão feita no chat e corrigiu a resposta dada.

Revisando o diálogo: Tetraedro - 4 faces, 6 arestas, 4 vértices. Vejam a dinâmica de uma aula "on-line": Os diálogos se intercalam e o professor, no caso eu, tenho que prestar muita atenção à tela para procurar a última linha que leu (Postado por João no fórum, um dia após o acontecido no chat). ${ }^{4}$

É nesse quadro, portanto, que tomam forma e sentido, as interações dialógicas: as pessoas nela envolvidas trocam ideias e um deve estar sempre bem atento à fala do outro. Tal como acontece nas interações face a face, ou talvez mais, no discurso em ambiente virtual que não ocorre em tempo real, instantâneo, o docente tem que estar sempre atento aos vários diálogos que ocorrem durante a comunicação na cena.

9. (26/11/2007 18h: 45 min) Prof. João fala para todos: Cubo:

10. (26/11/2007 18h: 46 min) Tutora Márcia fala para todos: Boa noite

11. (26/11/2007 18h: 46 min) Prof. João fala para Todos: 6 faces... 8 arestas... 8 vértices...

12. (26/11/2007 18h: 46 min) Prof. João fala para todos: Prisma: 7 faces... 15 arestas e 10 vértices.

13. (26/11/2007 18h: $47 \mathrm{~min})$ Tutora Silvia fala para todos: Professor eu contei 12 arestas no cubo.

14. (26/11/2007 18h: $47 \mathrm{~min})$ Tutor Fernando fala para Todos: 6 faces... 8 arestas... 8 vértices... de qual figura???

15. (26/11/2007 18h: 48 min) Prof. João fala para Todos: 12 arestas no cubo? Não... vá riscando

16. (26/11/2007 18h: 49 min) Tutor Fernando fala para Todos: 6 faces... 8 arestas... 8 vértices... de qual figura????? Cada uma delas, você verá que só tem $8^{5}$.

${ }^{4}$ COSTA; PAVANELLO, 2018. Recorte do fórum da interação geométrica do curso EAD, Paraná, 2018, Plataforma e-Proinfo.

5 COSTA; PAVANELLO, 2018. Recorte do chat cena 2 da interação geométrica do curso EAD, Paraná, 2018, Plataforma e-Proinfo. 
Nesta cena 2, João, ao esclarecer as dúvidas dos tutores sobre a quantidade de cada elemento das figuras enganou-se em sua resposta sobre o total de arestas do cubo, e o tutor, completamente confuso, insistia a todo o momento sobre a resposta dada.

Percebe-se no diálogo desta cena certa insatisfação na insistência do tutor Fernando quanto à resposta dada. O tutor deve ter verificado sua contagem e manifestou sua indignação nas sequências 14 e 16 por, até este momento, o docente não haver ainda esclarecido a questão. Na sequência 15, o docente pediu para o tutor riscar cada uma das arestas para confirmar o resultado. Mas havia nesta interação um embaraço que seria dissipado se uma figura fosse anexada ou até mesmo desenhada no instante do diálogo. Vejamos outro episódio intitulado inquietações:

1. (26/11/2007 18h: $51 \mathrm{~min})$ Tutor Fernando fala para todos: Que confusão.

2. (26/11/2007 18h: $51 \mathrm{~min})$ Tutora Célia fala para todos: Prof. pode explicar a questão 1 da primeira proposta de atividade da página105?

3. (26/11/2007 18h: $52 \mathrm{~min})$ Prof. João fala para todos: Sim...

4. (26/11/2007 18h: $52 \mathrm{~min})$ Prof. João fala para todos: Cada estudante desenhará um triângulo.

5. (26/11/2007 18h: 52 min) Prof. João fala para todos: .... Cada triângulo terá suas medidas angulares...

6. (26/11/2007 18h: $52 \mathrm{~min})$ Tutor Fernando fala para João: Por que não termina de informar os dados da tabela do exercício da página 52???????

7. (26/11/2007 18h: 53 min) Prof. João fala para todos: Mas todos os alunos perceberão que a soma dos ângulos internos será $180^{\circ}$ graus e assim por diante.

8. (26/11/2007 18h: $53 \mathrm{~min}$ ) Tutora Helena fala para todos: Em relação às medidas do ângulo, como posso classificá-los? Reto $90^{\circ}$, e os outros?

9. (26/11/2007 18h: 54 min) Prof. João fala para todos: Página 52 ?? Mas já falei as contagens não? ... falta alguma?

10. (26/11/2007 18h: $54 \mathrm{~min})$ Prof. João fala para todos: Ângulos: agudos, retos, obtusos.

11. (26/11/2007 18h: $54 \mathrm{~min})$ Tutor Fernando fala para todos: Informou ${ }^{6}$.

Nesse episódio temos a sequência do diálogo apresentado no episódio anterior, diálogo que preferimos separar em dois momentos em nossa análise. Também nessa cena 1 decidimos suprimir alguns discursos, priorizando os diálogos que realmente mencionavam os conteúdos da geometria.

Em sua primeira fala o tutor Fernando expressou sua inquietação com o rumo do discurso. Percebemos tal sentimento pela fala: "que confusão!", que traduz um sentimento de indignação pela resposta incorreta do docente.

${ }_{6}$ COSTA; PAVANELLO, 2018. Recorte do chat da interação geométrica do curso EAD, Paraná, 2018, Plataforma e-Proinfo. 
O tutor não conseguiu sua resposta, e o diálogo foi interrompido pela tutora Célia que levantou outra questão para o docente. Este responde à pergunta da tutora, sem parecer ter prestado atenção à intervenção de Fernando, o qual, no entanto insiste com o docente para que este resolva a atividade da página 52 e, na sequência do discurso, indaga: "Por que não termina de informar os dados da tabela do exercício da página 52?????????".

A maneira como o tutor escreve sua mensagem, com uma grande quantidade de pontos de interrogação, caracteriza, segundo (GIORDAN, 2008), um estilo voltado para chamar atenção do interlocutor. Se, por um lado, as mensagens da cena 1, referente ao diálogo com as tutoras Célia e Helena, desenvolvem-se na modalidade discursiva IRF (I corresponde ao início da troca, a pergunta; R refere-se à resposta e F ao feedback) utilizada por Giordan (2008), por outro lado, no tocante a Fernando tal modalidade IRF deixa de existir, por não haver a presença explícita de feedbacks.

Por se tratar de um curso a distância, presenciamos vários diálogos intercalados, o que dificultava a atenção do docente responsável pelo módulo de geometria. A ocorrência de vários diálogos ao mesmo tempo caracteriza-se, assim, como um problema recorrente de bloqueios de linguagem.

12. (26/11/2007 18h: 54 min) Tutor Fernando fala para todos: Quanto a arestas do cubo, por que são oito, e não $12 ? ? ? ? ? ?$

13. (26/11/2007 18h: 55 min) Prof. João fala para todos: Não sei Fernando! Acho que sim... deve estar aí para cima.

14. (26/11/2007 18h: 55 min) Tutor Fernando fala para João: Quanto a arestas do cubo, por que são oito, e não 12??????

15. (26/11/2007 18h: 55 min) Prof. João fala para todos: Cubo?

16. (26/11/2007 18h: 55 min) Célia fala para João: Prof. o senhor trocou a questão. É a 1 do alto da página 105.

17. (26/11/2007 18h: 56 min) Prof. João fala para todos: Cubo: só 8 arestas.

18. (26/11/2007 18h: $57 \mathrm{~min})$ Tutor Fernando fala para todos: tchau?

Nesta cena 2 do episódio inquietações, Fernando retoma a ideia da cena anterior e volta à pergunta: por que o número de aresta são oito e não doze? Por esta altura dos acontecimentos o tutor já deveria ter pesquisado, na internet ou em algum livro, pois ele está convicto de que a resposta do docente está errada. A insistência em perguntar sobre a aresta do cubo nos remete à atenção que Fernando dá a essa comunicação discursiva.

7 COSTA; PAVANELLO, 2018. Recorte do chat da interação geométrica do curso EAD, Paraná, 2018, Plataforma e-Proinfo. 
Nesta mesma interação ocorre a interrupção da tutora Célia que deseja suas tirar dúvidas sobre o material de apoio. Ao responder tal questão, o docente acaba interferindo no diálogo que mantinha com o tutor Fernando, que insiste em saber qual é realmente a quantidade de arestas existentes no cubo, perguntando:

"Quanto a arestas do cubo, por que são oito, e não 12?" Ao ler tal questão o docente exclama: "Não sei Fernando! Acho que sim ... deve estar ai para cima."

A análise da interação entre esses dois personagens talvez possa nos levar a classificá-la como a rejeição a um argumento de autoridade. Essa rejeição pode ser detectada no fato de Fernando cessar sua intervenção e sair do chat.

Até esse momento, o professor João não se dera conta do seu erro e insistia dizendo que no cubo há oito arestas. Só mais tarde, repassando o diálogo ocorrido no chat, percebeu seu equívoco e, com o objetivo de esclarecer as dúvidas de Fernando, postou no fórum a seguinte observação:

Fernando! Desculpe-me! Havia vários assuntos e diálogos paralelos e eu não conseguia perceber meu erro. Passando a limpo: No quadro referente às páginas 52 e 53 o correto é: Tetraedro: 4 faces, 6 arestas e 4 vértices. Cubo: 6 faces, 12 arestas e 8 vértices. Prisma pentagonal: 7 faces, 15 arestas e 10 vértices. Verifica-se o teorema de Euler, $\mathrm{V}+\mathrm{F}=\mathrm{A}+2$. (João comenta seu erro no fórum depois de repassar todo o diálogo). ${ }^{8}$

Neste momento o professor admite seu erro, ocorrido porque, preocupado em dar atenção a todos os tutores, não percebeu que havia dado uma resposta incorreta, confirmando serem oito as arestas do cubo. Observando o ocorrido, talvez possamos dizer que o tutor passou de aprendiz a avaliador das respostas do docente. Desta forma, a interação via on-line permite aos envolvidos uma troca de informação e talvez de papel, como assinala Giordan (2008).

Em conversas informais que tivemos com alguns dos tutores, esses comentaram que procuravam auxílio em outros materiais que não o material de apoio, o que de certa forma é bom, pois a construção do conhecimento deve ir além daquilo que lhe é oferecido (COSTA; PAVANELLO, 2010). Nesse sentido, cabe ressaltar as palavras de Bakhtin: "as ciências exatas são uma forma monológica do saber: o intelecto contempla uma coisa e emite enunciado sobre ela. Aí só há um sujeito: o cognoscente (contemplador) e falante (enunciador). A ele só se contrapõe a coisa muda" (BAKHTIN, 2003, p. 400).

A participação no espaço de interação é importante para o conhecimento que está sendo construído, isto é, não se pode simplesmente deixar de lado essas interações, estes momentos de diálogos, uma vez que é a partir dessa comunicação discursiva que as dúvidas serão sanadas e os conhecimentos e saberes poderão ser construídos.

8 COSTA; PAVANELLO, 2018. Recorte do fórum da interação geométrica do curso EAD, Paraná, 2018, Plataforma e-Proinfo. 


\section{Considerações finais}

Neste artigo procuramos analisar a comunicação estabelecida via internet entre os docentes universitários responsáveis pelo módulo de geometria e os tutores de formação docente, na modalidade Ensino a Distância, oferecido por uma universidade pública paranaense visando verificar se essa comunicação contribui, e de que modo para o trabalho a ser desenvolvido por esses tutores com os alunos do curso (os cursistas) em relação aos conteúdos desse conhecimento escolar. E, por entender que as ações a cargo do tutor neste contexto aproximam o seu trabalho ao de um professor, compreendemos que a formação de professores em um cenário virtual de aprendizagem deve ser objeto de estudos.

Com as gravações dos chats pudemos verificar dificuldades que são inerentes ao processo de comunicação e linguagem no EAD. No primeiro momento de análise percebemos que o próprio, episódio 1) Indagações é um episódio que faz com que os tutores e docentes em que uma discussão a respeito do tema tratado se torna difícil devido à dificuldade de comunicação em vários momentos. Outra questão relevante é o caso do episódio 2) Inquietação na própria plataforma, no qual podemos observar é que muitas vezes as escritas e as perguntas de um tutor não são realmente explicadas pelo docente universitário.

Separamos estes dois episódios, porque acreditamos que estes atos muitas vezes advêm neste tipo de comunicação on-line, principalmente quando tratamos de sujeitos que estão formando professores. As interações apresentadas nos mostram que a argumentação e comunicação entre o docente e o tutor necessitam de instruções mais substanciais para desempenhar a contento sua função de formação dos cursistas.

\section{Referências}

ALVES, L.; NOVA, C. (org.). Educação a distância: uma nova concepção de aprendizado e interatividade. São Paulo: Futura, 2003.

BAKHTIN, M. Estética da criação verbal. Tradução Paulo Bezerra. 4. ed. São Paulo: Martins Fontes, 2003.

BAKHTIN, M. Marxismo e filosofia da linguagem: problemas fundamentais do método sociológico da linguagem. Tradução Michel Lahud e Yara Frateschi Vieira. 13. ed. São Paulo: Hucitec, 2012. https://doi.org/10.1590/2176-457336646

BITTENCOURT, A. B. Editorial. Pro-Posições, Campinas, v.18, n. 3, p. 54, 2007.

BRASIL. Ministério da educação. Lei no 9.394, de 20 de dezembro de 1996. Estabelece as diretrizes e bases da educação nacional. Brasília, DF: Ministério da Educação, 1996. Disponível em: http://portal.mec.gov.br/seed/arquivos/pdf/tvescola/leis/lein9394.pdf. Acesso em: 11 ago. 2008. https://doi.org/10.11606/d.2.2017.tde-03102017-105747 
COSTA, A. L. P.; PAVANELLO, R. M. Formação de professores para o ensino fundamental I: a comunicação nos cursos a distância. Curitiba: Editora Appris, 2018. https://doi.org/10.18366/acrp.1012.2019

COSTA, A. L. P. A comunicação na fábrica educacional. In: ENCONTRO NACIONAL DE EDUCAÇÃO MATEMÁTICA, 6., 2018, Curitiba. Anais [...]. Curitiba: PUCPR, 2018. 1 CD-ROM.

COSTA, A. L. P.; PAVANELLO, R. M. Geometria nas séries iniciais e a formação de professores em um cenário virtual de aprendizagem. In: ENCONTRO NACIONAL DE EDUCAÇÃO MATEMÁTICA, 10., 2010, Salvador. Anais [...]. Salvador: UFBA, 2010. 1 CD-ROM. https://doi.org/10.17648/afnaeh-2010-74563

COSTA, A. L. P.; PAVANELlO, R. M. Tutores de um curso de licenciatura para os anos iniciais a distância e a matemática. In: CONFERÊNCIAS INTERAMERICANA DE EDUCAÇÃO MATEMÁTICA 50 ANOS DE CIAEM. 12., 2011, Recife. Anais [...]. Recife: UFPE, 2011. p. 1-10. https://doi.org/10.17648/afnaeh-2010-74563

D’ANTONIO, S. R.; PAVANELLO, R. M. Comunicação e argumentação nas disciplinas de prática pedagógica do curso de licenciatura em matemática da universidade estadual de Maringá. In: ENCONTRO NACIONAL DE EDUCAÇÃO MATEMÁTICA, 11., 2013, Curitiba. Anais [...]. Curitiba, PUCPR, 2013. 1 CD-ROM. https://doi.org/10.23925/1983-3156.2018v20i1p334-358

D' ANTONIO, S. C. O tutor e a formação inicial, em um curso na modalidade à distância, de professores que ensinam geometria nos anos iniciais do ensino fundamental. 2010. Dissertação (Mestrado em Educação para a Ciência e a Matemática) Universidade Estadual de Maringá, Maringá, 2010. https://doi.org/10.11606/t.48.2016.tde-09032016-103554

GIORDAN, M. Computadores e linguagens nas aulas de ciências: uma perspectiva sociocultural para compreender a construção de significados. Ijuí: Ed. Unijuí, 2008.

GOUVÊA, G.; OLIVEIRA, C. I. Educação a distância na formação de professores: viabilidades, potencialidades e limites. Rio de Janeiro: Vieira e Lent., 2006.

PAVANELLO, R. M. Comunicação e argumentação nas aulas de matemática. In: ENCONTRO NACIONAL DE EDUCAÇÃO MATEMÁTICA, 11., 2013, Curitiba. Anais [...]. Curitiba: PUCPR, 2013. 1 CD-ROM.

PERRENOUD, P. I. A formação de professores no século XXI. In: PERRENOUD, P. et al. (org.). As competências para ensinar no século XXI: a formação dos professores e o desafio da avaliação. Porto Alegre: Artmed, 2002. p. 11-33. https://doi.org/ 10.36229/978-85-7042-166-1.cap.03

REZENDE, F. A. A complexidade possível de ser transposta na conformação de ambiente de ensino e aprendizagem a distância. In: BRASIL, MINISTÉRIO DA EDUCAÇÃO (org.). Desafios da educação a distância na formação de professores. Brasília, DF: MEC, 2006. p. 127-150. https://doi.org/10.17143/ciaed/xxvciaed.2019.32869 
VALENTE, J. A.; BUSTAMANTE, S. B. V. (org.). Educação a distância: prática e formação do profissional reflexivo. São Paulo: Avercamp, 2009.

Recebido em: 18/9/2017.

Aprovado em: 20/12/2019.

Publicado em: 17/4/2020.

\section{Endereço para correspondência}

Alberto Luiz Pereira da Costa

Universidade Federal do Triângulo Mineiro

Instituto de Ciências Exatas, Naturais e Educação

Departamento Educação em Ciências, Matemática e Tecnologias

Rua Randolfo Borges Júnior, 1400, Bloco Novo, Unidade II

38064-200, Uberaba, MG, Brasil

\section{Autor:}

Alberto Luiz Pereira da Costa

Doutor em Educação pela Universidade Estadual Paulista "Júlio de Mesquita Filho" (FCT/UNESP), Professor Adjunto da Universidade Federal

do Triângulo Mineiro. Coordenador do Programa de Extensão Interfaces entre Artes, Ciências \& Matemática. Uberaba, MG, Brasil.

Orcid: http://orcid.org/0000-0002-5787-146X

E-mail: albertodacosta@terra.com.br 